\title{
High-Impact Practices for Transforming Online Learning
}

\author{
Theresa Conefrey \\ Santa Clara University
}

\author{
Davida S. Smyth \\ The New School
}

In spring 2019, in-person teaching, and extra-curricular campus activities suddenly stopped, and students found themselves taking classes online as campuses emptied and everyone was urged to "stay home." Instructors and students alike struggled with adapting to online teaching and learning at the same time as having to adapt to all the other changes of life during the COVID-19 pandemic. This paper briefly describes how we overcame this challenge by implementing high-impact practices (HIPs) such as ePortfolios, project-based learning, and undergraduate research in the humanities and science courses that we taught. We suggest that HIPs can promote student engagement to transform online learning.

Keywords: high-impact practices, online learning, STEM, undergraduate research

\section{INTRODUCTION}

In spring 2019, in-person teaching suddenly stopped and students who had been taking classes and engaging in extra-curricular and co-curricular activities suddenly found themselves taking classes online as campuses emptied and everyone was urged to "stay home." Students, who were accustomed to in-person learning, with the support of their instructors, classmates, and other on-campus support systems such as libraries, learning centers, and counselors, suddenly found themselves more responsible for their own learning than they had ever been before. Surveys at our institutions (a mid-size private, mostly undergraduate-focused, a Jesuit institution in northern California's Bay Area, and a private research university in New York City with a large proportion of international students) suggested that students were struggling to stay motivated to complete their work, that stress and anxiety were considerable challenges for them, that they were feeling concerned about their learning and their connection to peers and professors. Many felt overwhelmed with the amount of reading and assignments, and the time involved in reviewing lectures and trying to complete unfinished "lab" work. Others mentioned the lack of clarity in how the online courses were organized and the communication of expectations. A majority of students longed for more opportunities to connect with faculty and students. For first-year students, some of whom had not visited campus, there was also a feeling of disconnect from their institution. What they were missing were the aspects of the educational experience that typically promote student success: community, connection, a sense of belonging, and a growth mindset (Conefrey, 2018). 


\section{What High-Impact Practices Are and How They Help}

High-impact practices (HIPs) are a set of specific pedagogical practices that have been shown to meet these needs (Kuh, 2008). The American Association of Colleges and Universities lists these practices as the following: first-year seminars and experiences, common intellectual experiences, learning communities, writing-intensive courses, collaborative assignments and projects, undergraduate research, diversity/global learning, ePortfolios, service-learning or community-based learning, internships, and capstone courses and projects. A mounting body of research suggests that these practices support all learners and in particular, those that are disadvantaged or underrepresented and most at risk for not completing their college degrees (Finley \& McNair, 2013). HIPs align well with professional organizations focused on student learning in science (SENCER), engineering (KEEN), and the liberal arts in general (AAC\&U). Although not officially recognized until 2016 as one of these practices, we view ePortfolios as the most essential because they have the power to connect and amplify the other HIPs (Conefrey \& Smyth, 2020; Watson, Kuh, Rhodes, Light, $\&$ Chen, 2016). Figure 1 illustrates how these practices can be applied in all aspects of undergraduate education including majors, minors, co-curricular and extra-curricular activities.

These practices also align well with best practices in science education, which also encourage students to be more intentional about their studies and to take more responsibility for their own learning. For example, SENCER (Science Education for New Civic Engagements and Responsibilities) uses HIPs and evidence-based methods and strategies to improve undergraduate STEM education. This science education organization focuses on connecting science and civic engagement by teaching science through students' active participation in complex and unsolved public issues to get students excited about learning the necessary basic science knowledge and skills.

\section{HIPs Across the Undergraduate Curriculum}

HIPs can be used in both humanities and science courses and in vastly different types of institutions to strengthen students' abilities to apply what they are learning to authentic, real-world issues to improve their engagement in their learning and their intentionality about their programs of study. The examples below drawn from courses in English and Biology demonstrate how student motivation and understanding of what they were learning was improved despite the sudden transition to online teaching. They also demonstrate how students came to see that what they were learning could be applied to their lives after they graduated. 


\section{FIGURE 1 \\ INTEGRATING HIPS THROUGHOUT THE CURRICULUM}

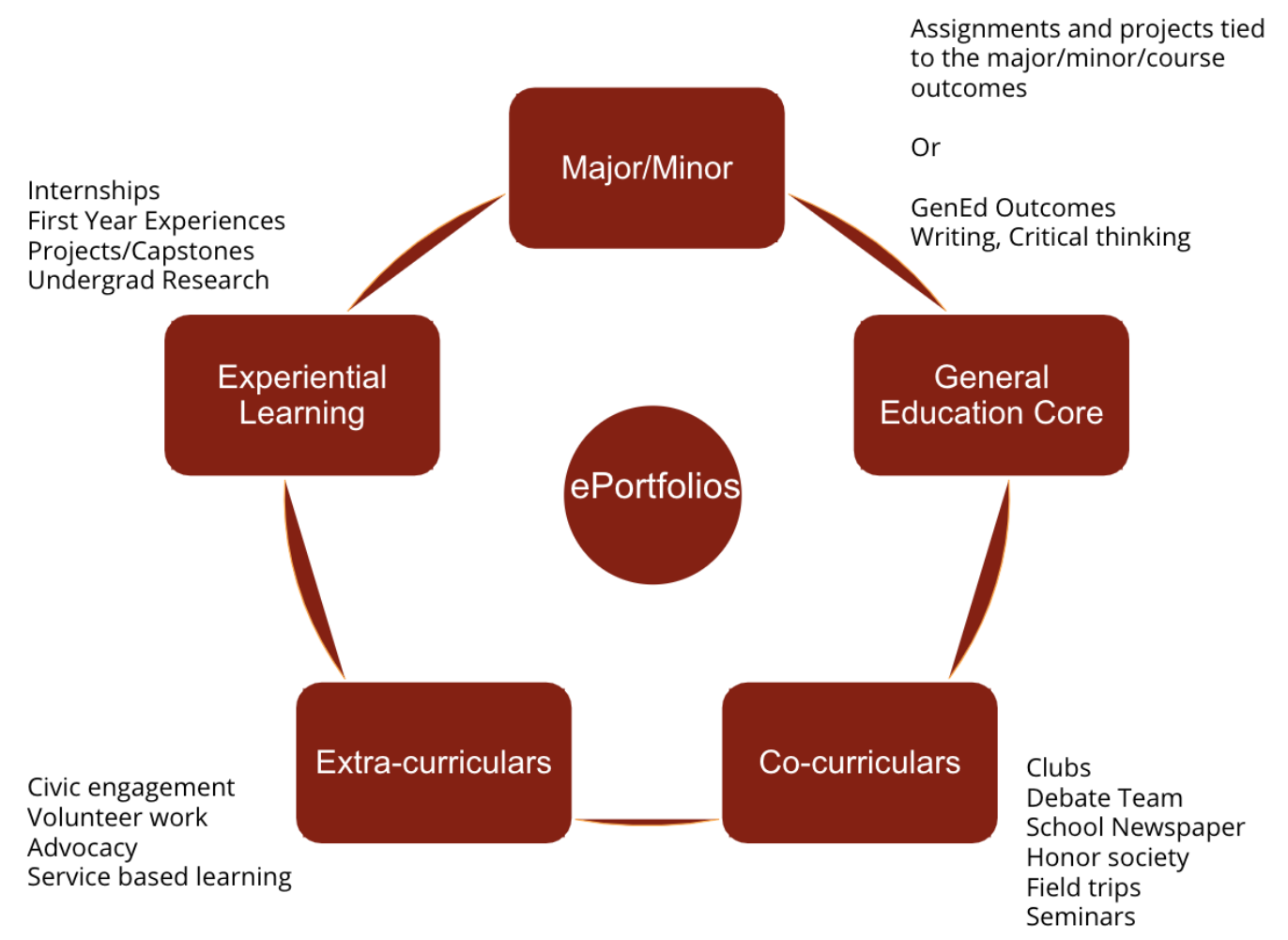

This figure shows how HIPS can be integrated throughout the curriculum and how eportfolios can play a central role.

\section{Using HIPs in an Online First-Year Writing Course}

When campus closed and in-person teaching was canceled, the students that I felt most concerned about were our new first-year students. These were recent high school graduates, who found themselves attending college from home and not being able to participate in the customary aspects of the first-year experience: dorm life, campus clubs, and extra and co-curricular activities. As a student's first college classes are crucial to his or her successful acculturation to college life, I knew that I needed to go beyond meeting the course learning goals of my first-year composition course to also building a virtual campus community, to make up for the sense of belonging that would usually happen by engaging in everyday campus life. I knew that I also needed to compensate for the development of an academic identity that would normally happen organically by taking college courses and interacting in co-curricular activities at Santa Clara University, a Private, Jesuit institution in Northern California's Bay Area with about 5,694 undergraduates.

At my institute, first-year writing functions in many ways like a first-year seminar because students are enrolled in the same two-sequence section as others in the same dorm and often even on the same floor as a way of helping students get to know each other and start forming a community. As no student can test out and there is only one Honor's course, students in each section represent a wide range of abilities and very different levels of preparation and comfort with college writing. Although all faculty teach to the same general learning outcomes typical of college writing courses everywhere (the ability to analyze the content and credibility of what they read, the ability to use writing to deepen their thinking and to compose effective nonfiction for different audiences and in a variety of modes), we choose our own topics for course materials. In keeping with the SENCER ideals, my sequence focuses on food justice, issues of food and sustainability, and global health issues related to food consumption. Equally, this topic connects students to the local and global community and aligns well with campus initiatives around sustainability. In addition, students are given sufficient latitude with essay topics that they can relate each essay to their current major or use it as 
an opportunity to explore a major if they do not have one already. Many of my students hope to major in STEM fields such as biology and public health and often choose to write their research papers on topics that foster civic scientific literacy.

With the goal of recreating this community-building digitally, I knew I needed to modify most of my existing assignments and create some new ones. Typically, my essay assignments all relate to the topic of food, with the main purpose of the first one being to gauge the general writing ability of my students and possibly identify any who might need extra help. The remaining assignments assess critical reading and research skills, and the final ePortfolio with reflection essay is to assess how well students have met the course learning outcomes and to encourage them to begin integrating their learning across the curriculum. When my course moved online, I modified the first essay assignment to make it an educational autobiography so that I could find out about my students' prior experience with writing. I made the second essay a review of a podcast rather than alphabetic text to emphasize the metaphor of writing as a conversation rather than a monologue and to give students a break from screens, and the third a podcast to continue the conversation metaphor and inspire students to think more creatively about a topic for their research-based essay. While the prompt for the reflection essay that anchored the ePortfolio remained the same, I used scaffolded questions to encourage students to compare and contrast more explicitly their skills at the beginning and end of the quarter.

In addition to adapting my assignments for online learning, I recruited past students to serve as peer educators, undergraduate students who had taken the course before, and who were interested in gaining leadership experience and course credit for their efforts. Based on interest surveys and self-introduction videos that I had students submit at the beginning of the quarter, I organized them into study groups, each led by a peer educator with similar interests or the same major. These peer educator-led study groups provided an opportunity for first-year students to get to know other first-year students, discuss the course content and ask questions about assignments that were unclear. Once students were comfortable speaking in the small groups, they were more willing to visit my virtual office hours and to participate actively in whole-class synchronous discussions. These sessions also focused on community-building by leading with warm-up conversations about hobbies and hometowns, what we were grateful for, how we were connecting to the campus, and our plans for holiday celebrations during the lockdown. For students who were more comfortable sharing their thoughts in a written format, I created discussion forums and collaborative assignments such as peer reviews, where students were organized in pairs and triads to share rough drafts of their work with each other. In addition to the choice of topic, students also had other options such as whether they wanted to create the podcast individually or as part of a student-selected group assignment. By giving students more agency, more choice of topics, and more modes for representing their ideas, I hoped they would assume more responsibility for their own learning.

These adaptations appeared to work well judging by assessments of student writing and feedback from anonymous narrative and numerical course surveys. Whereas I had struggled in prior quarters to help students break free of the tyranny of the five-paragraph essay format (thesis, three supporting ideas, and a conclusion), I learned from their educational autobiographical essays, that although many of them had felt constrained by this format that had been required since middle school, they also believed that this was what was required for college writing as well. As one of my students wrote in her first essay,

All of my paragraphs were formatted the same, starting with a topic sentence, then providing evidence (usually a quote), and finally analyzing the evidence. Perhaps the biggest change I made in my writing was abandoning the five-paragraph essay, or at least attempting to. From day one, we were told that this form of writing was limiting and that we should try to let go of it. Because my middle school and high school teachers had drilled this essay format into my head for so much of my academic career, it was difficult to let go of. The five-paragraph essay felt almost like a security blanket; it was familiar and reliable. 
Another gain from the adaptations was that students began to understand writing as a technology for thinking, a tool that had uses well beyond first-year writing and beyond college. Whereas one student had started his college career "doubting the value of writing", the same student noted in his reflection essay, "Writing during a pandemic has never been more important because leaders must articulate their thoughts efficiently and effectively to communicate their messages" and that if not, people would turn to unreliable social media such as Twitter for their information. Another student wrote that she hoped to be able to use what she had learned beyond the course and her college experience, that she wanted to be able to improve her written communication skills so that she could become "the best version" of herself "while making a meaningful difference" in her community. Similarly, recognizing the value of writing for critical thinking and civic engagement, one student commented,

The most important thing I learned was that using writing as a tool for learning and discovery can help you question your own actions. For example, after writing several assignments, I was able to reevaluate how I was leaving an environmental footprint and how I could be more proactive.

While the virtual classroom could not replace the in-person classroom community-building process, the PE-led study groups, the discussion posts, peer reviews, and other collaborative assignments appeared to build a supportive digital environment that helped ease the transition from high school to college for these new college students. Working with the PEs and collaborating with other classmates helped bridge the digital distance and help students feel more connected to a campus that some of them had never visited. In their reflection essays, students wrote about how much they had enjoyed being able to view and respond to what other students had written that they had gone above and beyond the assignment expectations. Discussing the podcast assignment where students recorded their own analysis and commented on the analyses of two other students, one male wrote, "I enjoyed learning about what everybody wrote so much that instead of just listening to two posts and finishing the assignment, I ended up listening to almost all the submissions."

\section{ePortfolios in a First-Year Writing Course}

Students' ePortfolio assignments also revealed that they were beginning to develop an academic identity. Telling and retelling their stories in their ePortfolio pages helps students figure out who they are and who they want to become. Below is an example from a student who identified himself as a "business major from Chicago, IL":

Displayed on this website are some of my writing samples from English I to showcase my work for employers and others. In my samples, I focus my discussion on food sustainability, specifically relating it to seafood. I try to bring notice to the ways our Earth is being harmed while also providing ways everyone can make a difference.

In their About Me pages, students included excerpts from their essays, photos of their hometowns, and iconic pictures from visits to campus. Additionally, the digital media skills they were acquiring help prepare them for intelligent, responsible, and creative citizenship. In their ePortfolio Welcome pages, many students identified their majors and acknowledged multiple audiences and the affordances of digital communication. The example below (Figure 2), from a student show identified as a biology major shows an understanding of visual rhetoric and digital navigation skills. 
FIGURE 2

\section{THE WELCOME PAGE OF AN EPORTFOLIO FROM A FIRST-YEAR WRITING COURSE}

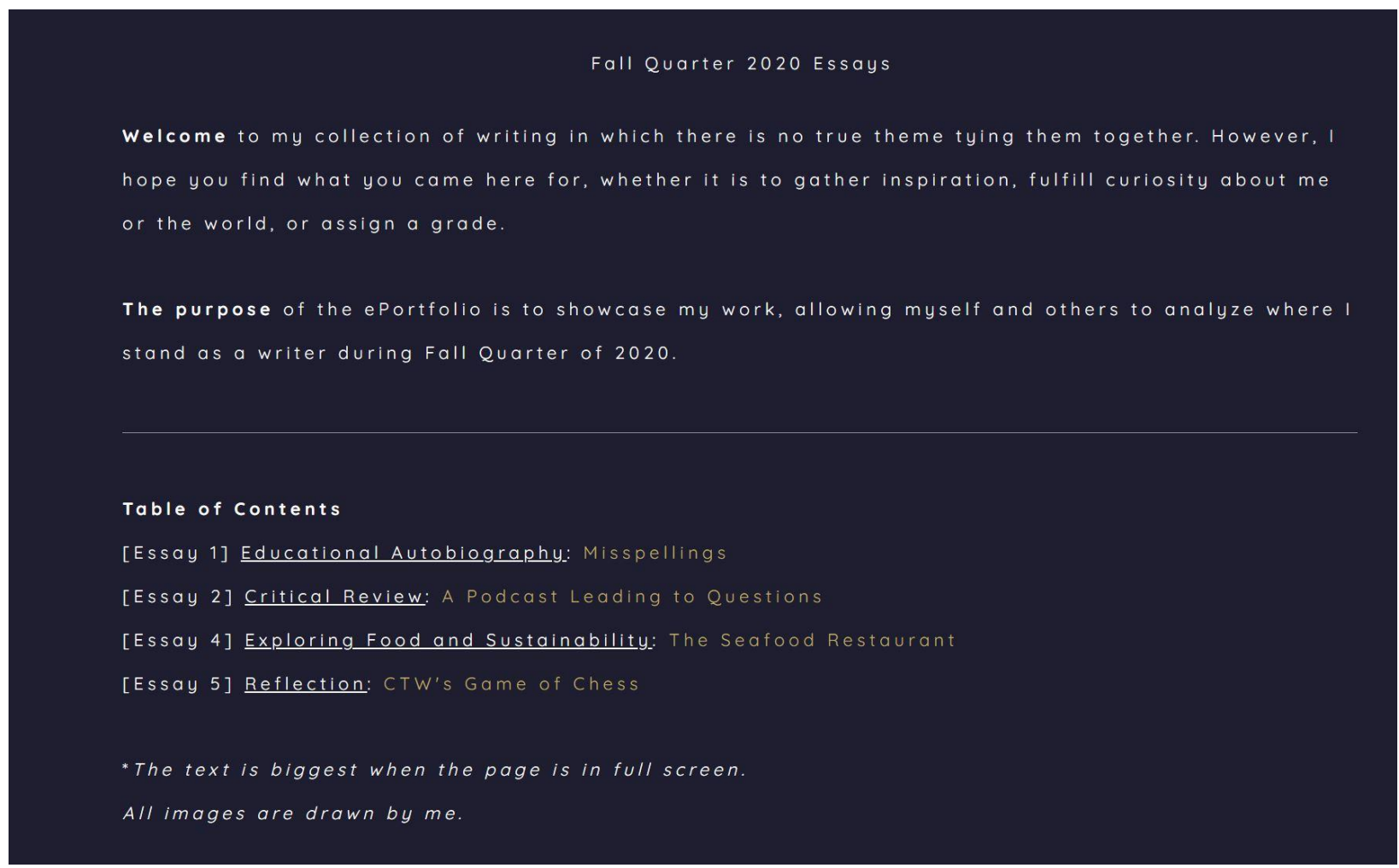

This figure shows the welcome page of an eportfolio from a first-year writing course.

\section{Can You Be Hands-On With STEM Classes When Online?}

Going online with classes posed a particular challenge for STEM faculty, as STEM pedagogy is often closely tied to "hands-on", "activity-based" learning experiences which are deployed in lab settings. STEM students learn science by doing science, and active learning in conjunction with authentic, real-world focused, lab activities have served as a foundation for much of our recent innovation in STEM teaching, particularly for courses that align with the SENCER ideals (American Association for the Advancement of Science, 2011). The rapid transition from a face-to-face, lab-based setting to a fully online setting in Spring 2020 was a shock to many STEM faculty who had not prepared to teach online and were not trained for online instruction. We had no contingency plan for this. Lab-based pedagogy cannot be simply delivered at home, particularly in my discipline of microbiology. Safety considerations and a need for supervision along with access to equipment, technology, and reagents were possibly the greatest barriers to providing a seamless transition to online learning this past Spring. Faculty had to adapt and alter their delivery, syllabuses, and curriculum rapidly and collaboratively. HIPs such as first year experiences, writingintensive courses, collaborative assignments, and projects as well as undergraduate research all have a considerable impact when used in STEM disciplines. As with the examples from the humanities above, we have found that combining HIPs in our courses can have an even greater impact when delivered face-toface, but whether they could be effectively combined in an online environment was yet to be seen. The pandemic provided a unique situation in which to evaluate their efficacy, when combined, across the disciplines.

Despite the lack of access to laboratories and technology, you can in fact "do-science" when online. In fact, the need to move online presented a reckoning for many STEM educators and we experienced a realignment of our understanding of what was critically important for our students to learn. The scientific process involves asking questions, formulating hypotheses, analyzing data, and conducting experiments 
along with presenting data, and reviewing and considering the work of others. There are many existing strategies and tools that can be administered online that allow students to experience much of the scientific process and they can actively participate in the process as well.

\section{Collaborative Assignments and Projects}

In Spring 2020 I was teaching Evolution, Mutation and Computation, a course aimed at introducing majors and non-majors to the theory of evolution, the modeling of biological concepts and processes, and the use of Avida-Ed for an authentic research experience with digital life-form evolution (http:/avidaed.msu.edu). The HIPs I combined were authentic research and collaborative assignments and projects. I collaborated with Anne Yust, a colleague who was a Mathematics Instructor to introduce the students to the modeling of biological concepts (Yust \& Smyth, 2020). While we were in-person, Anne worked with the students to create a simulation of bacteria growth in NetLogo and she adapted a book chapter we had written (Yust \& Smyth, 2018), to create a scaffolded tutorial for students to work up to simulating mutation and competition over the next three sessions. Owing to the pandemic we had to abandon our original plan and focus on simulating relevant aspects of COVID-19. So, we shifted our focus from evolution and mutation to the spread of infectious disease. The online environment worked well for instruction in modeling as it allowed Anne to share her screen via Zoom while the students followed along; the students had the NetLogo platform open next to the shared NetLogo screen, allowing them to reproduce the actions Anne was performing. Anne leveraged newspaper articles that used models and simulations and students were able to use Google docs to collaborate and document their models, and we used breakout rooms for small-group work. The capstone assignment for this course was an authentic research project with AvidaEd. One of the groups asked to use Netlogo instead for their research project investigating transmission of infectious disease and used the code Anne had provided and modified it to include additional elements of the built environment in the model such as buildings, cleaning regimens, and even vaccinations. Remarkably, the group took the initiative and produced slides and a companion that could be used to educate other students in the use of their modified model, going above and beyond the course requirements. This particular group included students who had taken my SENCERized research course, The Microbiome of Urban Spaces in a prior semester and were working with me to investigate the role of the built environment in the spread of antibiotic-resistant bacteria. An additional student in the group had taken Anne's first-year mathematics-flavored seminar class where they used NetLogo to simulate a variety of social and physical phenomena. It was fascinating to see the students make connections to their other courses while integrating the knowledge they had gained through their research experiences. One of the students remarked: "How do you design spaces around an infectious disease? ... It's helping us understand the way that you can look at something that's affecting the whole world right now in the classroom".

\section{Undergraduate Research}

At that time, I was also teaching the Microbiome of Urban Spaces, an authentic classroom undergraduate research experience. I had been teaching this SENCERized course for several years (Smyth, 2018) and for The New School, I had adapted it to include the preparation of libraries for DNA sequencing on the iSeq, a DNA sequencer I have in my lab. The rapid transition to online instruction meant that I could not have my students continue their DNA sequencing projects. So, I leaned onto my colleagues at Research Experiences in Microbiomes Network, REMNet (https://qubeshub.org/community/groups/remnet) and Tiny Earth, a community dedicated to the identification of novel antibiotic-producing bacteria (https://tinyearth.wisc.edu/) who were working to identify ways we could substitute existing resources for various steps in the process from DNA extraction to sequence analysis. These online resources were shared across the community via emails, newsletters, and social media. Certain lab-based skills cannot be practiced easily at home such as DNA isolation and sequencing, but I was able to maintain some elements of the normality of prior semesters that worked just as well in the online environment, as shown in Figure 2, which shows the workflow for a microbiome experience in the classroom. Some aspects translated easily online (preparation and analysis) whereas other elements needed to be supplemented with virtual labs, videos, and simulations. 
One of the important elements of the scientific method is recognizing and crediting the work of other scientists. I instructed students in the use of Zotero, a free citation manager that can also be used to generate collaborative bibliographies that students can contribute to, a platform I had used in my face-to-face courses. I also encouraged the students to keep a Google document in which to generate an annotated bibliography, which was helpful when they were working in groups on a collaborative paper/project. The use of such a simple citation manager encourages students to practice citing their references and giving credit to the work of others.

One of the most challenging aspects of science courses is reading and engaging with scientific literature. I had previously developed and implemented many strategies for effective and active reading in my faceto-face courses such as annotation, word maps, and concept maps. To help students engage with the literature and the work of other scientists in the online environment, I used Hypothes.is, a freely available, online program that can be used as a standalone (there is a chrome extension) or it can be integrated into a learning management system to support annotation of files and PDFs (Goller, C., Vendegrift, M., Cross, W \& Smyth, D.S, 2020). With Hypothes.is an instructor can set up assigned readings with reading prompts and suggest tags that students can use to annotate and highlight text. Most importantly, they can do their annotations collaboratively and in real-time. I combined my approach with Science in the Classroom (https://www.scienceintheclassroom.org/) which provides examples of annotated papers to demonstrate how papers can be annotated to highlight important terms, previous work, results and discussion, and news and policy links.

\section{FIGURE 3}

\section{THE WORKFLOW FOR A MICROBIOME EXPERIENCE IN THE CLASSROOM}

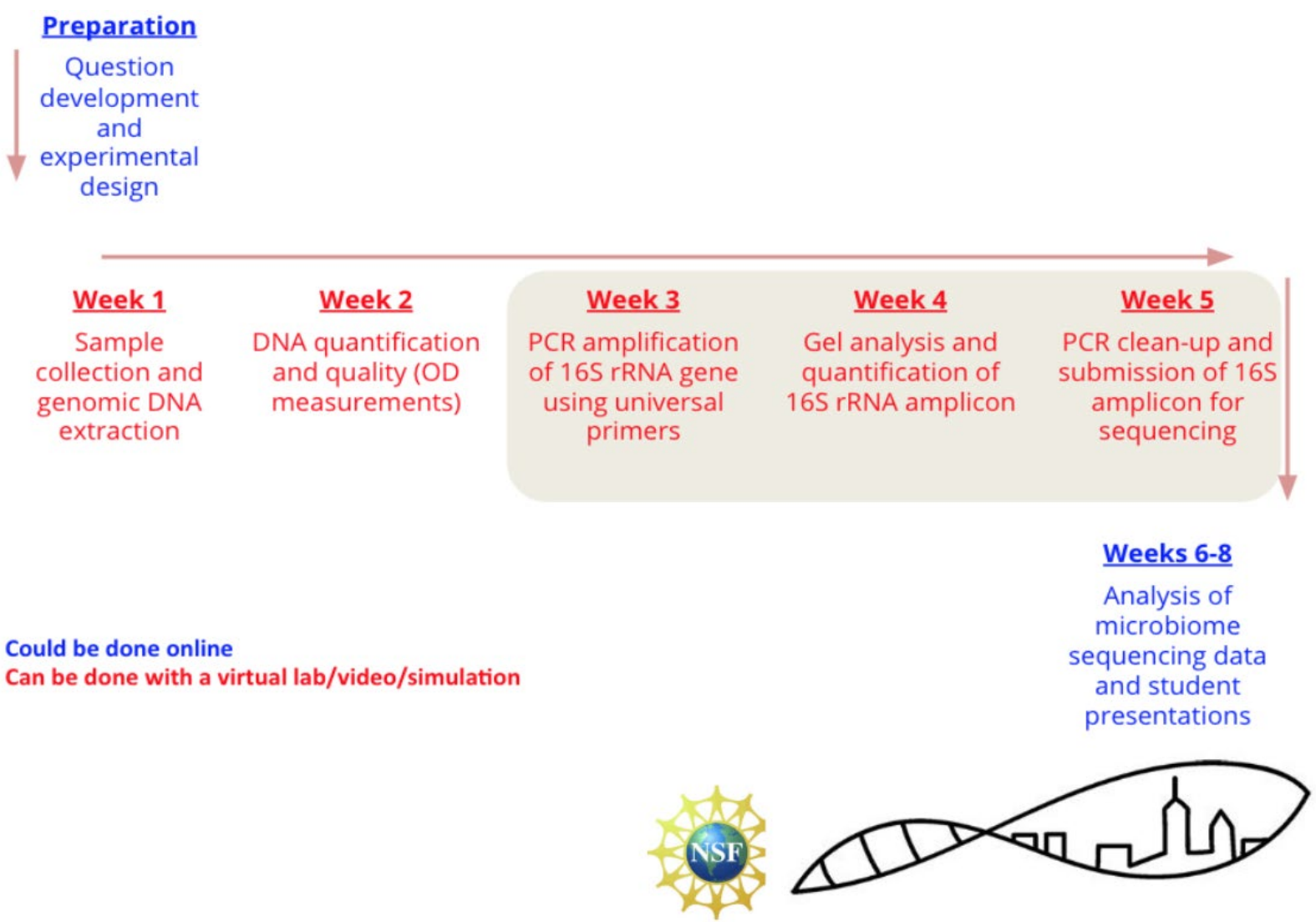

This figure shows the workflow for a microbiome experience in the classroom. Some aspects of the flow translated easily online (preparation and analysis) whereas other elements needed to be supplemented with virtual labs, videos and simulations. 
I had long used an online notebook for my students. Benchling is a freely available platform for sharing protocols and lab notebooks in your course. Again, you can set it up so that students can see each other's entries and collaborate, and peer review each other's work. Rubrics help with grading. Students in my Spring course had been in my Fall courses and had already used Benchling. By using Benchling across several of my courses, students practiced how they were recording their experiments and the quality and professionalism of their entries increased. By sharing examples of student's work, I was able to reinforce best practices for recording experiments and activities in the online format.

In the STEM field, scientists often present their work at conferences and symposia in the form of posters. To mirror this practice, I have had students generate posters in many of my courses as an alternative to the research paper. This practice is more authentic, and by scaffolding the use of posters across several courses, students get to practice and improve their poster design and poster presentation skills. I've used Padlet in several of my courses to facilitate online poster sessions and to display the projects and creative works generated by students during the semester. We've also adopted the use of QR codes that can be scanned to bring the reader to the student research papers (Figure 4).

\section{FIGURE 4}

\section{STUDENT POSTERS, PROJECTS, AND CREATIVE WORKS DISPLAYED USING PADLET}

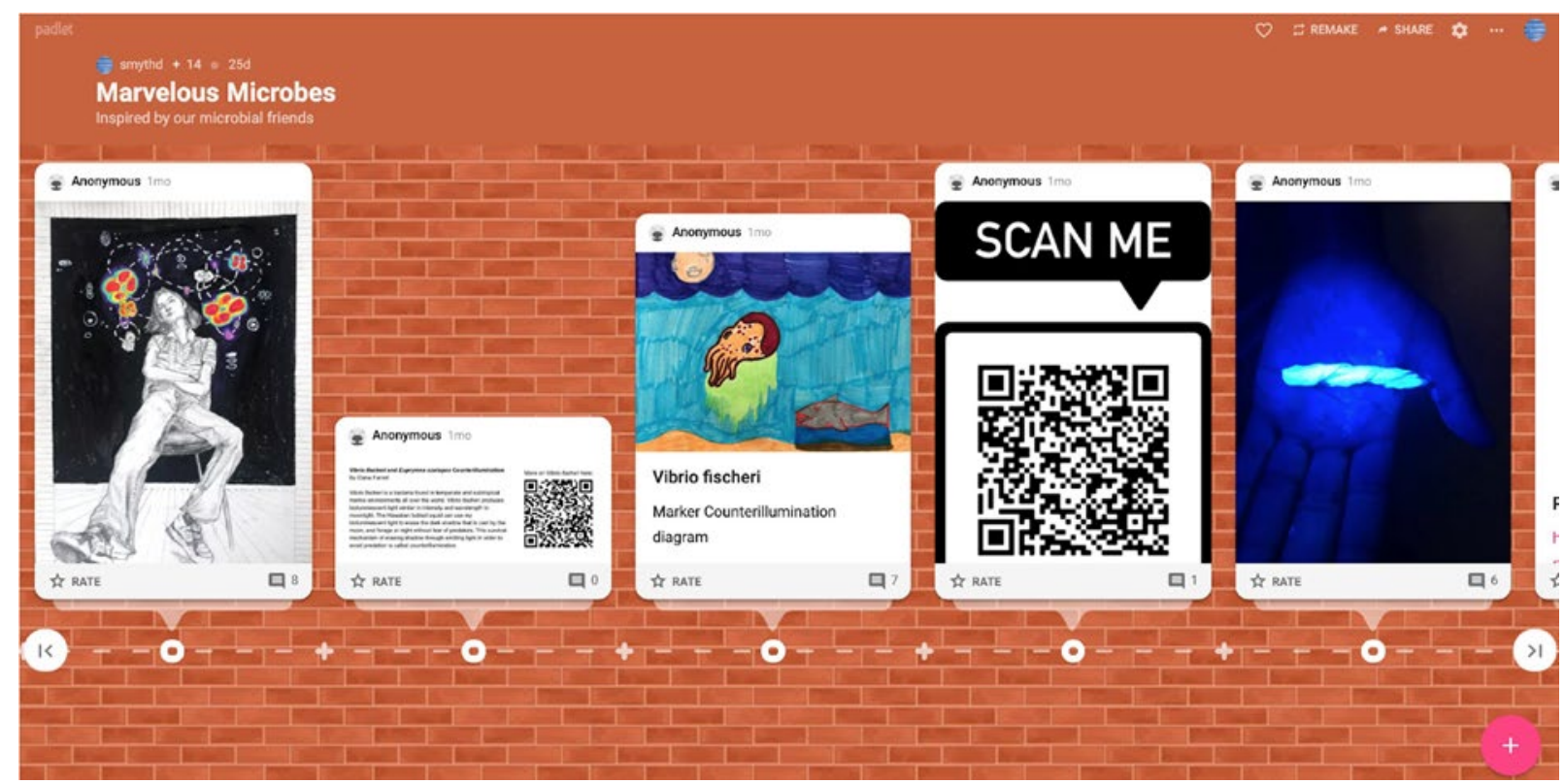

Student posters, projects, and creative works can be displayed using padlet. This style allows for a gallery walk through the student products.

\section{Observations, Questions, and Hypotheses}

Not all science happens in a laboratory. As a consequence, students can perform experiments at home. They can make observations, generate questions, and formulate hypotheses. When instructors focus on the essence of the concept or phenomenon they are trying to explore, they can often find ways to mirror and mimic activities that they would generally conduct in the teaching lab. They can have students measure, describe, and draw phenomena. Foldscopes can be sent to students. They can use USB microscopes. There are now portable PCR machines, gel apparatus, and even portable DNA sequencers. Students can upload their observations to databases and contribute to the scientific process online. The New York Botanical Garden (NYBG) along with iNaturalist offers opportunities for this (https://www.nybg.org/plant-researchand-conservation/center-for-conservation-strategy/ecoquest-challenge/). We owe a debt of gratitude to our colleagues in informal STEM settings, and our colleagues who conduct community science who have made much of their tools, tips and strategies available to us in informal settings. 
To have students experiment at home, I went back to the process of science and identified ways that students could conduct labs safely. I used Winogradsky columns to teach my students about microbial communities at home. Sourdough cultures can be used to explain experimental design and fermentation. Glo Germ can be used to model infectious disease transmission on surfaces as well as how to wash one's hands effectively. There are many ways we can adapt our laboratory protocols and methods so that they work at home, at low cost, and show the same or similar learning outcomes.

\section{Analyzing Data}

Students can gather and interpret data. There is a wealth of existing data sets available online from QUBES to SERC to Data Nuggets. By analyzing existing data and gathering their own, students can learn and practice analytical skills. Students can use Excel and Google Sheets to generate simple plots. They can use existing models and simulations to learn scientific concepts. Depending on the situation, they can generate and test their own models such as by using NetLogo (Yust \& Smyth, 2020). Virtual labs can be used to substitute for hands-on lab activities. VR experiences can be substituted. There are several opportunities to integrate data analysis using R and GIS.

\section{Reflecting, Discussing, and Considering Science's Role in Society}

The online environment is perfect for encouraging discourse around the role of science in society. There are many ways to engage students in the study of public perception of science, the role of science in policy and justice, equity, and diversity in science. As mentioned, ePortfolios are a wonderful way to encourage students to reflect on topics, readings, or class discussions. Students can also reflect upon and comment on the work of their peers. Discussion boards can be used in learning management systems or technology can be used that allows dynamic open discussion such as Jamboard. Padlet works well for discussions (See Figure 5) and I have used it for reflections and online discussions in all of my courses. Students can also reach out to scientists by emailing them, they could interview scientists via Zoom or connect to organizations online.

\section{FIGURE 5}

\section{THE SOCIAL JUSTICE ISSUES STUDENTS IDENTIFIED BY STUDENTS}

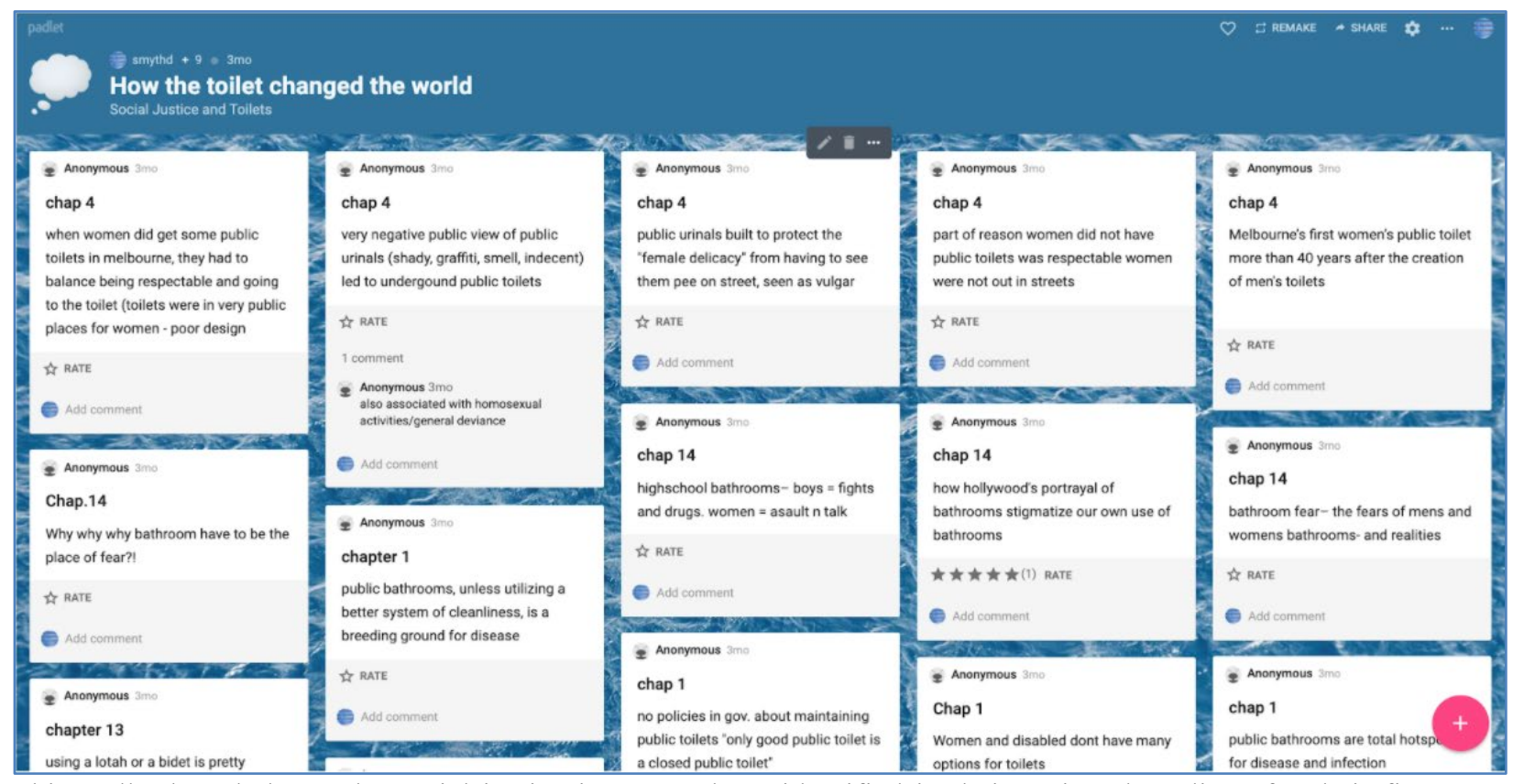

This padlet board shows the social justice issues students identified in their assigned readings for their first year seminar class "How the toilet changed the world". 
Perhaps one of the most powerful ways to engage students is through the use of narrative and case studies. There are several repositories of case studies online including the National Center for Case Study Teaching in Science (https://sciencecases.lib.buffalo.edu/). In addition, there is considerable interest in connecting high-throughput big data studies to case study pedagogy such as the High-throughput Discovery Science and Inquiry-based Case Studies for Today's Students. Lastly, my favorite HIP remains the ePortfolio. I have used this HIP for student reflections and for projects for several years. Like Benchling, my students use ePortfolios in their first-year experience for displaying their reflections as well as their assignments and projects and also use them when they take the first course in the major "Microbial Ecologies". As we continued to be online in Fall, I used ePortfolios as before and the practice worked just as well online. In fact, owing to the differences in time zones for my students, the use of the ePortfolios allowed students to engage with one another according to their schedules.

\section{Building Community Online}

The loss of face-to-face, human contact, and interaction presents a huge challenge to growing and sustaining a sense of community.

\section{Community Building With Your Colleagues}

The transition to an online environment posed a challenge to growing and sustaining a sense of community among the faculty. This was rapidly eased using Zoom and other online meeting platforms. What would normally have required a space, and a commute to that space, travel and sharing of schedules, now was simply a click of a switch. The Zoom space, being used daily for our classes was an easy transition for all of us. While we would not have normally seen all of the faces of our colleagues at departmental meetings, now we were seeing a gallery of faces, and sharing our thoughts and challenges in the chat window. In the Spring especially in New York City, the use of Zoom for our school meetings was a critical buffer from the sadness and the isolation of lockdown and for the sharing and dissemination of ideas and best practices. In STEM fields, there was a rapid blossoming of community building and efforts to support one another, through the sharing of teaching resources, to coffee hours to virtual meetups.

\section{Community-Building With Your Students}

There are several ways you can grow a sense of community among your students. We found that inviting former and present students to join sessions as peer educators, or peer mentors can build a sense of connection to the campus as they share their experience and mentor and guide students through the challenges of the college experience. Best of all, these peer educators had experienced the transition to online learning themselves and could empathize with the more junior students. Technology can also help. Our colleagues have used additional tools to support online learning. Group annotation can be achieved using Perusal and Kami. Students (or faculty) can record themselves using TikTok or generate Podcasts and use Slack to facilitate group collaboration and effective communication. VoiceThread generates collaborative, multimedia slideshows that enable embedded images, documents, and videos. Students can navigate these slides and leave voice or text comments or add videos or audio files. Kahoot, Plickers, and Poll Everywhere can facilitate pop quizzes and polls and word clouds. Menti helps create interactive presentations. Wakelet allows curation of links, social media posts, videos, and images as items to later be organized into private or public collections. Flipgrid allows teachers to post topical videos essentially videos with some accompanying text that can be shared with students for their responses. Jamboard and Mural allow for group collaboration that mimics a whiteboard or Post-its. Zoom sessions can be started with warmups, ice breakers, and simple check-ins in the chat. Zoom also has an annotation feature that you can use in class during live sessions where students can annotate directly onto your slides. You can use polls and breakout rooms as well as google docs for online collaboration. Students have enjoyed creating group podcasts, as well as self-introduction videos. Probably the simplest approach is to simply use periodic check-in messages to communicate care and promote connection with your students. 


\section{Using ePortfolios and Other HIPS in Your Courses}

As we mentioned in discussions of our courses, we believe that ePortfolios are one of the most powerful HIPs because they can be used in conjunction with other HIPs to amplify their impact. We have used ePortfolios in several of our courses from first-year seminars to microbiology courses. Even if you were new to ePortfolios, there are likely to be many ways that you could leverage them in your courses. For example, students could display their topical research papers on an ePortfolio or upload their reflective papers. They could comment and discuss each other's ePortfolios on the ePortfolios themselves. Alternatively, they could create 1-minute papers, or digital stories or videos and display them on their ePortfolios. ePortfolios can be used by students to display their work for multiple audiences such as instructors, program assessment, employers, or the public. In sharing their work with others, they begin to learn the power and importance of forms of media for communicating their learning effectively.

\section{CONCLUSIONS}

Students and faculty alike appreciate opportunities for interaction with their peers to create a sense of community. It is important to create multiple virtual opportunities for students to interact with each other and in small groups early and often at multiple points throughout the term. Coursework and group projects alone might not be enough to lead to meaningful interactions and can be particularly challenging for new students, especially during the pandemic. We have offered informal online spaces for students to connect with and work alongside one another both asynchronously and synchronously.

\section{Asynchronous Options Provide Opportunities to Connect}

We find that offering options for students asynchronously along with live sessions works best. A completely asynchronous experience is not what students appreciate. Offering a mixture affords flexibility for students' study schedules and allows for shorter recordings and modules that students appreciate. Recordings can help deepen student understanding of key concepts, which is important for review and exam preparation and these can be generated in response to particular needs of students that emerge in the live sessions. Students can choose how to interact with these materials, viewing them once or watching them repeatedly to clarify concepts and prepare for exams.

\section{Synchronous Options Provide Opportunities to Connect}

A fully online structure can meet the need for face-to-face contact between faculty, students, and their peers and colleagues while providing a space for discussion and real-time Questions \& Answers. Live sessions can also help create predictability in weekly schedules while encouraging accountability. We have learned that live sessions can be used to support a variety of types of formal and informal learning: whole class, small groups, one-on-one meetings, and collaborative, project-based learning. 


\section{REFERENCES}

American Association for the Advancement of Science. (2011). Vision and change in undergraduate biology education: A call to action. Retrieved from https://visionandchange.org/

Conefrey, T. (2018). Supporting first-generation students' adjustment to college with high-impact practices. Journal of College Student Retention: Research, Theory \& Practice. doi:10.1177/1521025118807402

Conefrey, T., \& Smyth, D.S. (2020). Reflecting, integrating, and communicating knowledge through ePortfolios to increase civic and scientific literacy. The International Journal of ePortfolio, 10(1), 1-18. Retrieved from https://www.theijep.com/pdf/IJEP352.pdf

Finley, A., \& McNair, T. (2013). Assessing underserved students' engagement in high-impact practices. Washington, D.C.: Association of American Colleges and Universities. Retrieved from https://leapconnections.aacu.org/system/files/assessinghipsmcnairfinley_0.pdf

Goller, C., Vendegrift, M., Cross, W., \& Smyth, D.S. (2021). Annotating and Co-creating with Hypothesis and Google Docs. Accepted to Journal of Microbiology and Biology Education.

Kuh, G.D. (2008). High-impact educational practices: What they are, who has access to them, and why they matter. Washington, DC: Association of American Colleges \& Universities.

Smyth, D. (2017). An authentic course-based research experience in antibiotic resistance and microbial genomics. Science Education and Civic Engagement: An International Journal, 8(2), 59-65.

Smith, D.S., \& Yust A. (2020). Practicing and Simulating Social Distance. Science Education and Civic Engagement: An International Journal, 12(2), 80-81.

Yust, A., \& Smyth, D.S. (2019). Simulating Bacterial Growth, competition, and resistance with AgentBased Models and Laboratory Experiments. In H.C. Highlander, A. Capaldi, \& C.C. Eaton (Eds.), An Introduction to Undergraduate Research in Computational and Mathematical Biology: From Birdsongs to Viscosities. Birkhauser.

Watson, C.E., Kuh, G.D., Rhodes, T., Light, T.P., \& Chen, H.L. (2016). Editorial: ePortfolios - The eleventh high impact practice. International Journal of ePortfolio, 6(2), 65-69. 